\title{
Pseudomyxoma Peritonei
}

Erev E. Tubb M D, PGY-3

The patient is a 78 year-old male with a past medical history of hypertension and duodenal ulcer presenting with 2 months of increasing abdominal girth. The patient reports 1 month of loose bowel movements and a 2 week history of early satiety. He notes that in the last week he has been nauseous at the smell and thought of food. He denies fevers, chills, excessive alcohol intake, history of blood transfusions, intravenous drug use, melena or bright red blood per rectum. The patient states he has never undergone a colonoscopy and to his knowledge there is no family history of malignancy.

The patient was admitted to the hospital and a diagnostic study was performed. The images from a CT scan demonstrate multiple loculated fluid collections with enhancing walls within the peritoneal cavity. The largest mass was located anteriorly within the peritoneal cavity and measured $30 \mathrm{~cm} \times 14 \mathrm{~cm}$ (transverse $x$ AP) and extended from the liver to the bladder. These finding were consistent with a pseudomyxoma peritonei and the patient was taken to surgery for an exploratory laparotomy. The patient underwent an evacuation of the gelatinous tumor and an ileocecal resection with primary ileoascending colostomy. The pathology report reveal ed the origin of the mucinous secretions was in fact an appendiceal cystadenocarcinoma.

Pseudomyxoma peritonei is a rare condition resulting from rupture of a mucocele of the appendix, a mucinous ovarian cyst, or mucin-secreting intestinal or ovarian adenocarcinoma. It is two to three times more common in females than in males. It is often an unexpected finding during a laparotomy and is said to be found in 2 of every 10,000 laparotomies.
The primary treatment remains surgical debulking although the rate of recurrence in the twelve-year $M$ ayo Clinic series was $76 \%$ with $50 \%$ of recurrences in the first 2.5 years. It is not clear if adjuvant radiotherapy and/or chemotherapy is beneficial. The five-year survival rate ranges from 53 to $75 \%$, but outcomes vary widely between relatively benign and malignant subgroups. Patients with appendiceal cystadenocarcinomas with pseudomyxoma peritonei have a $25 \%$ five-year survival rate, with most deaths attributed to intestinal obstruction or renal failure. The study of pseudomyxoma peritonei is limited by the rarity of the condition and the small number of cases collected in published series.

\section{References}

1. Landen S, Bertrand C, M addern GJ, et al. Appendiceal mucoceles and pseudomyxoma peritonei. Surg Gynecol O bstet 1992; 175:401.

2. Gough DB, D onohue JH, Schutt AJ, Gonchoroff N, Goellner JR, Wilson TO et al. Pseudomyxoma peritonei. Long-term patient survival with an aggressive regional approach. Ann Surg 1994; 219: 112-19.

3. M ann WJ Jr, Wagner J, Chumas J, Chalas E. The management of pseudomyxoma peritonei. Cancer 1990; 66: 1636-40.

4. M isdraji J, Yantiss RK, Graeme-C ook FM, Balis UJ, Young $\mathrm{RH}$. Appendiceal M ucinous $\mathrm{N}$ eoplasms: A clinicopathologic analysis of $107 \mathrm{C}$ ases. American Journal of Surgical Pathology 2003; 27(8):1089-1103.

5. Esquivel J, Sugarbaker PH . C linical presentation of the pseudomyxoma peritonei syndrome. British Journal of Surgery 2000; 87(10):1414-1418.

6. Sugarbaker, PH Shmookler, B.; Ronnett, B. M. Chang, D. Pseudomyxoma peritonei. British Journal of Surgery 1999; 86(6):842. 